This document is confidential and is proprietary to the American Chemical Society and its authors. Do not copy or disclose without written permission. If you have received this item in error, notify the sender and delete all copies.

\title{
Mesoporous Metal-Nitrogen-Doped Carbon Electrocatalysts for Highly Efficient Oxygen Reduction Reaction
}

\begin{tabular}{|r|l|}
\hline Journal: & Journal of the American Chemical Society \\
\hline Manuscript ID: & ja-2013-07552k.R2 \\
\hline Manuscript Type: & Communication \\
\hline Date Submitted by the Author: & 13 -Oct-2013 \\
\hline Complete List of Authors: & $\begin{array}{l}\text { Liang, Hai-Wei; Max-Planck-Institut für Polymerforschung, } \\
\text { Wei, Wei; Max-Planck-Institut für Polymerforschung, } \\
\text { Wu, Zhong-Shuai; Max-Planck-Institut für Polymerforschung, } \\
\text { Feng, Xinliang; Max-Planck Institute for Polymer Research, Synthetic } \\
\text { Chemistry } \\
\text { Mullen, Klaus; Max-Planck-Institute for Polymer Research, }\end{array}$ \\
\hline
\end{tabular}

SCHOLARONE ${ }^{\text {Ix }}$

Manuscripts 
For commercial viability, proton-exchange-membrane (PEM) fuel cells must overcome the barrier of high cost caused by the exclusive use of platinum-based catalysts, particularly at the cathode, due to the slow kinetics of the cathodic oxygen reduction reaction (ORR). ${ }^{1}$ To develop lowcost alternative catalysts with high activity and durability in ORR, great efforts have been devoted to synthesizing heteroatom (e.g., nitrogen or/and phosphorus, boron, sulfur)doped, nanostructured carbon materials that exhibit an ORR performance comparable to that of commercial $\mathrm{Pt} / \mathrm{C}$ catalysts in alkaline media because of their unique electronic properties and structural features. ${ }^{2}$ PEM fuel cells can only be operated with acidic electrolytes, however, as insoluble carbonates derived from $\mathrm{CO}_{2}$ ultimately poison the fuel cell in a basic medium. ${ }^{3}$

The addition of certain transition metals (e.g., Fe, Co) to the metal-free, nitrogen-doped carbon frameworks results in a non-precious metal (NPM) catalyst system with improved ORR activity in acidic media. 4 Although some breakthroughs were recently attained by the careful selection of suitable nitrogen/transition metal precursors and carbon

\begin{abstract}
A family of mesoporous non-precious metal (NPM) catalysts for oxygen reduction reaction (ORR) in
acidic media, including cobalt-nitrogen-doped carbon (C-N$\mathrm{Co})$ and iron-nitrogen-doped carbon (C-N-Fe), was prepared from vitamin B12 (VB12) and the polyaniline-Fe
(PANI-Fe) complex, respectively. Silica nanoparticles, ordered mesoporous silica SBA-15, and montmorillonite were used as templates for achieving mesoporous structures. The
most active mesoporous catalyst was fabricated from VB12 and silica nanoparticles and exhibited a remarkable ORR activity in acidic medium (half-wave potential of $0.79 \mathrm{~V}$,
only $\sim 58 \mathrm{mV}$ deviation from Pt/C), high selectivity (electron transfer number > 3.95), and excellent electrochemical stability (only $9 \mathrm{mV}$ negative shift of half-wave potential after 10,000 potential cycles). The unprecedented perfor-
mance of these NPM catalysts in ORR is attributed to their well-defined porous structures with a narrow mesopore size to $572 \mathrm{~m}^{2} / \mathrm{g}$ ), and homogeneous distribution of abundant metal- $\mathrm{N}_{\mathrm{x}}$ active sites.
\end{abstract}

supports, as well as optimization of the synthetic conditions, ${ }^{4-5}$ achieving comparable activity and durability of the NPM catalysts with the state-of-the-art Pt/C catalyst remains a challenge. Two crucial factors govern the performance of NPM catalysts, i.e., (i) elemental composition and the interactions between different components, which determine the intrinsic nature of active sites; and (ii) specific surface area and porous structure, which determine the accessible part of active sites and the transport properties of ORR-relevant species $\left(\mathrm{H}^{+}, \mathrm{e}^{-}, \mathrm{O}_{2}, \mathrm{H}_{2} \mathrm{O}\right) .4,6$ The traditional method for preparing NPM catalysts involves direct pyrolysis of the mixture of nitrogen, carbon, and transition metal precursors and frequently fails in controlling the porous structure, thus leading to limited exposure of the ORR active sites and relatively poor transport properties. 4

Herein, we demonstrate a family of NPM catalysts with well-controlled mesoporous structures using template synthesis. Silica colloid (12-nm $\mathrm{SiO}_{2}$ nanoparticles dispersed in water), ordered mesoporous silica SBA-15, and montmorillonite (MMT, a layered clay with a two-dimensional open channels) were employed as templates to realize the mesoporous structures of NPM catalysts (Figure S1). These templates are highly efficient for fabricating mesoporous carbon-based materials..$^{2 b, 2 c, 7}$ Vitamin B12 (VB12) and a polyaniline-Fe (PANI-Fe) complex were selected as precursors for preparing the $\mathrm{C}-\mathrm{N}-\mathrm{Co}$ and $\mathrm{C}-\mathrm{N}-\mathrm{Fe}$ mesoporous NMP catalysts, respectively (Figure S1). The high N/C atomic ratios of these two precursors (0.22 for VB12, 0.17 for PANI) allow for the production of doped carbons with a high nitrogen content after pyrolysis.5c,5d The prepared C-N-Co and C-NFe catalysts possess well-defined mesoporous structures, a high Brunauer-Emmett-Teller (BET) surface area (up to 572 $\mathrm{m}^{2} / \mathrm{g}$ ), and nitrogen content (up to $9.5 \%$ ). The mesoporous catalysts described here offer the desirable combination of a highly accessible surface area and an efficient transport path, resulting in an improved ORR performance in acidic media.

To synthesize mesoporous C-N-Co catalysts (see Figure S1 and the details of fabrication process in Supporting Information), various template materials were first dispersed in VB12 solution under vigorous stirring before evaporation of the water. The obtained solid composites were then thermally treated under flowing nitrogen at $600-900{ }^{\circ} \mathrm{C}$ and finally etched in hydrofluoric acid to remove the templates. 
The resulting $\mathrm{C}-\mathrm{N}-\mathrm{Co}$ catalysts are denoted as $\mathrm{VB} 12 /$ Silica colloid, VB12/SBA-15, and VB12/MMT, according to the templates used during the synthesis. For comparison, carbon-supported catalyst VB12/C was also prepared using carbon black (Vulcan $\mathrm{XC}-72 \mathrm{R}$ ) as a support.
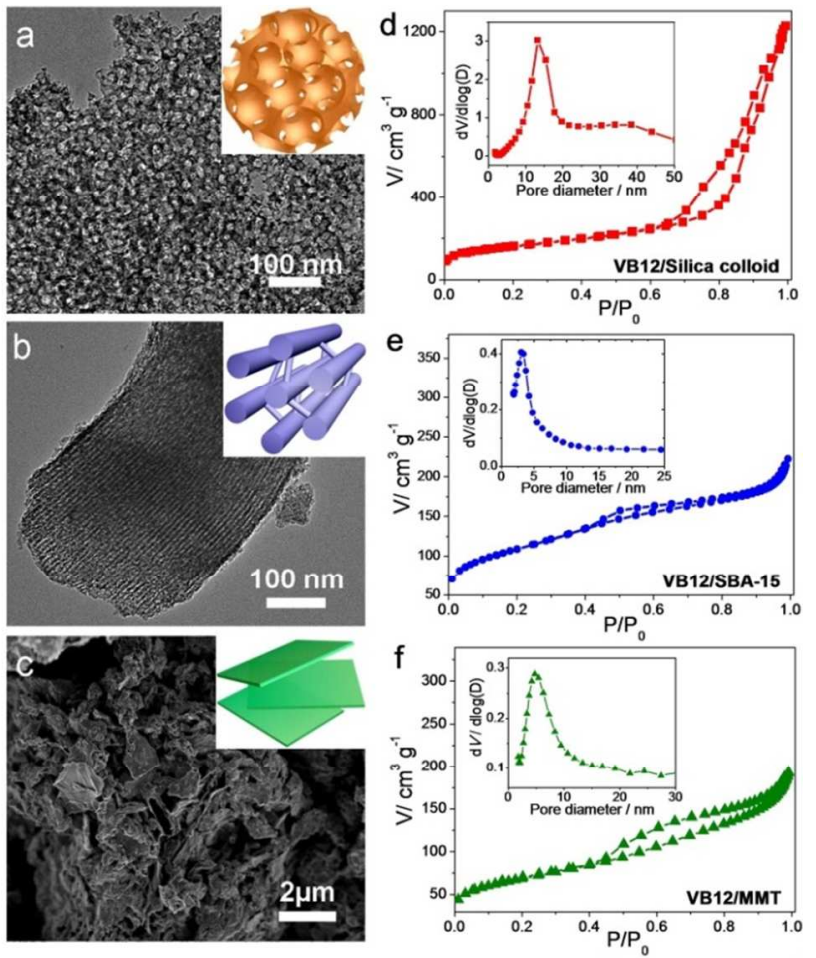

Figure 1. (a,b) TEM images and (c) SEM image of asprepared C-N-Co catalysts: (a) VB12/Silica colloid, (b) VB12/SBA-15, and (c) VB12/MMT. Insets in (a-c) are the model illustration of the catalysts with various mesoporous structures. (d-f) $\mathrm{N}_{2}$ sorption isotherms of these three C-NCo catalysts. Insets show the pore size distribution from the BJH method of corresponding samples.

The microstructures of the C-N-Co catalysts were first examined by transmission electron microscopy (TEM) and scanning electron microscopy (SEM). Interconnected vesicle-like frameworks, a well-defined linear array of mesoporous structures, and nanosheet-like structures were observed for the VB12/Silica colloid, VB12/SBA-15, and VB12/MMT catalyst, respectively (Figure 1a-c and Figure S2a-c). These observations well reflected the geometric characteristics of the original templates and indicated successful introduction of the porous features for these catalysts. VB12/C catalyst inherited the spherical morphology of carbon support (Figure S2d). The textural properties of the $\mathrm{C}-\mathrm{N}-\mathrm{Co}$ catalysts were investigated by $\mathrm{N}_{2}$ adsorptiondesorption isotherms and are summarized in Table S1. The remarkable hysteresis loops indicate the mesoporous nature of these C-N-Co catalysts (Figure 1d-f). The BET surface areas of these three catalysts were $568 \mathrm{~m}^{2} / \mathrm{g}$ (VB12/Silica colloid), $387 \quad \mathrm{~m}^{2} / \mathrm{g} \quad$ (VB12/SBA-15) and $239 \mathrm{~m}^{2} / \mathrm{g}$ (VB12/MMT), all of which were much higher than that of VB12/C $\left(134 \mathrm{~m}^{2} / \mathrm{g}\right)$. The mesopore size distribution was centered at $12.0 \mathrm{~nm}, 3.5 \mathrm{~nm}$, and $4.5 \mathrm{~nm}$ for VB12/Silica colloid, VB12/SBA-15, and VB12/MMT, respectively, according to the Barrett-Joyer-Halenda (BJH) model (insets in Figure 1d-f), whereas VB12/C showed a broad pore size distribution in the entire testing range (1.8-178 $\mathrm{nm}$ ) (Figure S3). Notably, major surface areas of the three templated catalysts comprised mesopores (Table $\mathrm{S} 1$ ), especially the VB12/Silica colloid (mesopore surface area $462 \mathrm{~m}^{2} / \mathrm{g},>80 \%$ of total surface area).

X-ray photoelectron spectroscopy (XPS) analysis was performed to analyze the content and chemical state of the nitrogen and cobalt in the C-N-Co catalysts (Table S1, Figure $\mathrm{S}_{4-\mathrm{S}} 7$ ). The nitrogen and cobalt content of the three templated catalysts was almost the same (9.3-9.5 at\% $\mathrm{N}$ and 1.3-1.4 at\% $\mathrm{Co}$ ) and much higher than that of $\mathrm{VB} 12 / \mathrm{C}$ (2.3 at\% N, 0.79 at\% Co) (Table $\mathrm{S} 1$ ). The self-supporting feature of the templated catalysts thus leads to a high N/Co content and principally high density of active sites, while the use of carbon black as a support for preparing the VB12/C catalyst dilutes the precursor molecules and results in a relatively low $\mathrm{N} / \mathrm{Co}$ content in the final pyrolyzed products (Table S1). The high-resolution N1s spectra of all C-N-Co catalysts were fitted with three different signals having binding energies of $398.7 \mathrm{eV}, 399.8 \mathrm{eV}$, and $400.9 \mathrm{eV}$, corresponding to pyridinic $\mathrm{N}$, pyrrolic $\mathrm{N}$, and graphitic $\mathrm{N}$, respectively (Figure S5). ${ }^{8}$ The peak at a binding energy of $398.7 \mathrm{eV}$ should also include a contribution from nitrogen bound to the metal $(\mathrm{Me}-\mathrm{N})$, due to the small difference between binding energies of $\mathrm{N}-\mathrm{Me}$ and pyridinic $\mathrm{N} .{ }^{8 b, 9}$ Pyridinic $\mathrm{N}$ (probably including $\mathrm{Me}-\mathrm{N}$ ) and graphitic $\mathrm{N}$ are generally believed to participate in the active sites. ${ }^{2 \mathrm{~d}, 8 \mathrm{~b}, 9-10}$

Although there was a significant amount of cobalt species (1.3-1.4 at\%) in the templated C-N-Co catalysts, as indicated by XPS analysis (Table S1), we hardly observed any metal-containing nanoparticles by TEM inspection because the etching agent (hydrogen fluoride) dissolves both the inorganic templates and metal/metal oxide nanoparticles. ${ }^{11} \mathrm{X}$ ray diffraction (XRD) pattern further proved the absence of crystalline metal/metal oxide phases (Figure S8). The highresolution Co $2 \mathrm{p}_{3 / 2}$ spectrum of $\mathrm{VB} 12 /$ Silica colloid can be deconvoluted into two peaks with binding energies of 781.6 $\mathrm{eV}$ and $779.7 \mathrm{eV}$ (Figure S6), which correspond to nitrogenand oxygen-coordinated metals respectively. ${ }^{12}$ Besides nitrogen and cobalt, the templated catalysts had a significant amount of oxygen species (Figure S7 and S9), which is due to the oxygen implantation by the inorganic templates. ${ }^{13}$ It has been widely reported that the metal-oxygen site exert limited contribution to the total catalytic activity of ORR in acidic media, ${ }^{12}$ although metal oxides and $\mathrm{Me}-\mathrm{O}_{\mathrm{x}}$ sites have exhibited considerable activity in alkaline media. ${ }^{14}$ The possible contribution of a small amount of phosphorus element to the ORR activity was also excluded (Figure S9).

Elemental mapping with sub-nanoscale energy-filtered TEM (EFTEM) imaging reveals that both the nitrogen and cobalt species are homogeneously distributed throughout the whole mesoporous structure (Figure S10). Importantly, the cobalt and nitrogen signals are highly overlaid with each other (Figure S10). Although the exact nature of the active sites in NPM catalysts remains unknown until now, there is a consensus that a metal species stabilized by nitrogen coordination must be present for generating catalysts with reasonable activity and durability in acidic environment. 4 Based on the EFTEM mapping as well as XPS and TEM analysis, the cobalt species that survived after acid leaching are uniformly distributed in the carbon/nitrogen matrix at the atomic or sub-nanoscale level, which are believed to contribute to highly active $\mathrm{Me}-\mathrm{N}_{\mathrm{x}}$ active sites. ${ }^{15}$ Indeed, $\mathrm{X}$ ray absorption fine-structure ${ }^{15,16}$ and Mößbauer analyses ${ }^{15}$ have been reported to confirm the metal-nitrogen binding 
configurations. Overall, the well dispersed $\mathrm{Co} / \mathrm{N}$ sites, combined with easily accessible porous structure, are highly beneficial for the electrocatalytic performance (see below).
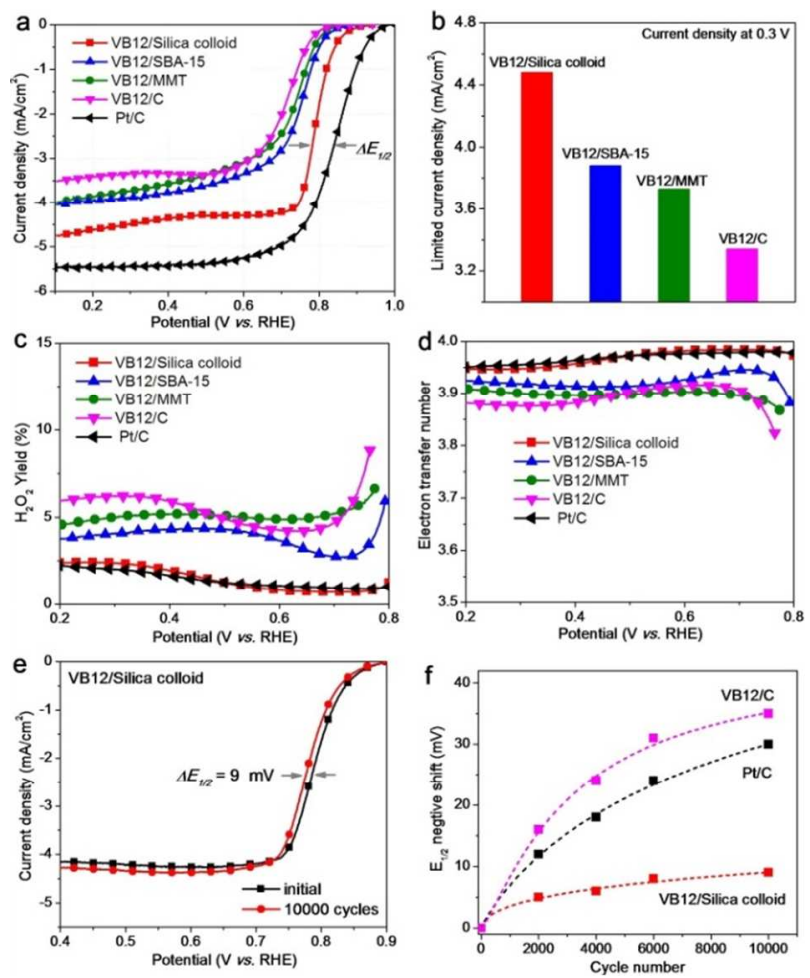

Figure 2. (a) ORR polarization plots of different $\mathrm{C}-\mathrm{N}-\mathrm{Co}$ catalysts. Electrode rotation speed, $1600 \mathrm{rpm}$; scan rate, 10 $\mathrm{mV} / \mathrm{s}$. (b) Limited current density of various C-N-Co catalysts at $0.3 \mathrm{~V}$. (c) $\mathrm{H}_{2} \mathrm{O}_{2}$ yield and (d) electron transfer number of different $\mathrm{C}-\mathrm{N}-\mathrm{Co}$ catalysts and $\mathrm{Pt} / \mathrm{C}$ as functions of the electrode potential. (e) ORR polarization plots of VB12/Silica colloid before and after 10,000 potential cycles in $\mathrm{O}_{2}$-saturated electrolyte. (f) Negative shift of the halfwave potential $\left(\mathrm{E}_{1 / 2}\right)$ of $\mathrm{VB} 12 /$ Silica colloid, VB12/C, and $\mathrm{Pt} / \mathrm{C}$ catalysts with the number of $\mathrm{CV}$ cycles under $\mathrm{O}_{2}$.

The electrocatalytic properties of the as-fabricated C-NCo catalysts toward ORR were evaluated using rotating ring-disk electrode (RRDE) techniques in $0.5 \mathrm{M} \mathrm{H}_{2} \mathrm{SO}_{4}$ at room temperature. For comparison, a state-of-the-art Pt/C (20 wt. \% Pt, BASF) catalyst was also tested in $0.1 \mathrm{M} \mathrm{HClO}_{4}$ to avoid performance loss caused by bisulfate adsorption. ${ }^{5,17}$ We first studied the ORR activity of the mesoporous NPM catalyst as a function of the pyrolysis temperature in the range of $600^{\circ}-900^{\circ} \mathrm{C}$ by taking the VB12/Silica colloid catalysts as a typical example. The best ORR activity was achieved at $700{ }^{\circ} \mathrm{C}$, as revealed by the onset and half-wave potentials in the ORR polarization plots (Figure S11), probably because an optimal balance of surface area, active site density, and electron conductivity were realized at this temperature. ${ }^{2 b, 9,15 a}$ Therefore, the VB12based catalysts discussed below were all produced at $700{ }^{\circ} \mathrm{C}$ unless otherwise specified.

The steady-state ORR polarization curves indicated that all three templated $\mathrm{C}-\mathrm{N}-\mathrm{Co}$ catalysts had higher activity than VB12/C in terms of onset potential and half-wave potential (Figure 2a). In particular, VB12/Silica colloid manifested the highest ORR activity among all C-N-Co catalysts (Figure 2a, also see the Tafel plot in Figure S12) and exhib- ited an ORR half-wave potential of $0.79 \pm 0.02 \mathrm{~V} v$ s reversible hydrogen electrode (RHE), which is comparable with the best values of NPM catalysts reported in literature ${ }^{5 \mathrm{c}, 10}$ and only $\sim 58 \mathrm{mV}$ deviation from a state-ofthe-art Pt/C catalyst (20 $\mu \mathrm{g} \mathrm{Pt} / \mathrm{cm}^{2}$, BASF). Additionally, all three templated catalysts showed a higher limiting current density at $0.3 \mathrm{~V}\left(4.5 \mathrm{~mA} / \mathrm{cm}^{2}\right.$ for $\mathrm{VB} 12 /$ Silica colloid, 3.9 $\mathrm{mA} / \mathrm{cm}^{2}$ for VB12/SBA-15, and $3.7 \mathrm{~mA} / \mathrm{cm}^{2}$ for VB12/MMT) than VB12/C catalysts $\left(3.3 \mathrm{~mA} / \mathrm{cm}^{2}\right)$ (Figure $2 \mathrm{~b}$ ), attributable to the access to large quantity of active sites and improved mass-transport properties as a result of mesoporous structures..$^{\mathrm{b}}$ Furthermore, we observed a strong correlation between the activity and apparent BET surface area of the C-N-Co catalysts (Figure S13), although the three templated catalysts possessed an almost identical nitrogen and cobalt content (Table S1), undoubtedly indicating the importance of the porous structure of the NMP catalyst for ORR.

The selectivity of the four-electron reduction of oxygen for as-prepared $\mathrm{C}-\mathrm{N}-\mathrm{Co}$ catalysts and $\mathrm{Pt} / \mathrm{C}$ was further studied using the RRDE technique. The potential of the Pt ring electrode in the RRDE system was set to $1.23 \mathrm{~V}$ for detecting peroxide species formed at the disc electrode. Remarkably, the $\mathrm{H}_{2} \mathrm{O}_{2}$ yield of VB12/Silica colloid catalysts remained below $2.5 \%$ at all potentials and dropped to $0.71 \%$ at $0.7 \mathrm{~V}$, corresponding to a high electron transfer number of 3.98 (Figure 2c and 2d). In addition, loading experiments ${ }^{18}$ revealed that the $\mathrm{H}_{2} \mathrm{O}_{2}$ yield measured with $\mathrm{VB} 12 /$ Silica colloid catalysts had little loading dependence (Figure S14). Even at a low loading of $0.1 \mathrm{mg} / \mathrm{cm}^{2}$, the electron transfer number was still larger than 3.8 at $0.4 \mathrm{~V}$, suggesting an intrinsic four-electron-transfer process.

We performed accelerated durability tests by cycling the catalysts between 0.6 and $1.0 \mathrm{~V}$ at $50 \mathrm{mV} / \mathrm{s}$ under oxygen atmosphere to evaluate the electrochemical stability of the C-N-Co catalysts. After 10,000 continuous potential cycles, the half-wave potential $E_{1 / 2}$ of VB12/Silica colloid exhibited a negative shift of only $9 \mathrm{mV}$ (Figure 2e), which is much lower than most reported values for NMP catalysts, $5 \mathrm{c}, 19$ carbon-supported VB12/C catalyst (35 mV negative shift, Figure S15a), and even Pt/C (30 mV negative shift, Figure S15b), suggesting the excellent durability of VB12/Silica colloid catalysts in acidic medium (Figure 2f). The extremely low $\mathrm{H}_{2} \mathrm{O}_{2}$ yield $(0.71-2.5 \%)$ of the VB12/Silica colloid catalyst would be beneficial to its electrochemical stability. On the other hand, the active sites were homogeneously distributed in the carbon matrix of the self-supported mesoporous VB12/Silica colloid catalysts. Even though the top layer of the catalyst was destroyed during the accelerated durability tests, the supplemental active sites in sub-layers were exposed and accessible to the electrochemical interface to boost the ORR durability. ${ }^{8}$

To confirm the significance of the porous structure on the ORR performance of NPM catalysts, we also prepared mesoporous $\mathrm{C}-\mathrm{N}-\mathrm{Fe}$ from a polyaniline-Fe complex using silica colloids $(12 \mathrm{~nm})$ as templates. The characteristics of the mesoporous structure were thereby observed by TEM visualization (Figure 3a) and $\mathrm{N}_{2}$ adsorption-desorption isotherms (Figure S16). Similar to the previous C-N-Co system, the mesoporous $\mathrm{C}-\mathrm{N}-\mathrm{Fe}$ catalyst possessed a narrow pore size distribution (average pore diameter, $14 \mathrm{~nm}$ ), larger specific surface area $\left(572 \mathrm{~m}^{2} / \mathrm{g}\right)$, and higher nitrogen/metal content (8.8 at\% nitrogen and 1.5 at\% iron) than a carbon black-supported catalyst (surface area $153 \mathrm{~m}^{2} / \mathrm{g}$, nitrogen content 6.5 at\%, and iron content 0.98 at\%) (Table S1). Importantly, the electrochemical study showed that the 
mesoporous $\mathrm{C}-\mathrm{N}-\mathrm{Fe}$ catalyst exhibited much better ORR performance than the carbon black-supported catalyst (Figure $3 \mathrm{~b}$ and Figure S17). The onset and half-wave potentials for the PANI-Fe/Silica colloid estimated from the ORR polarization plots were 0.84 and $0.73 \mathrm{~V}$, respectively, and were much higher than those of PANI-Fe/C catalyst (0.78 and $0.54 \mathrm{~V}$, respectively) (Figure $3 \mathrm{~b}$ ). Moreover, the PANI$\mathrm{Fe} /$ Silica also exhibited outstanding four-electron selectivity (electron transfer number 3.95 at $0.5 \mathrm{~V}$ ), in contrast to the PANI-Fe/C catalyst (electron transfer number 3.59 at $0.5 \mathrm{~V}$ ) (Figure S17).
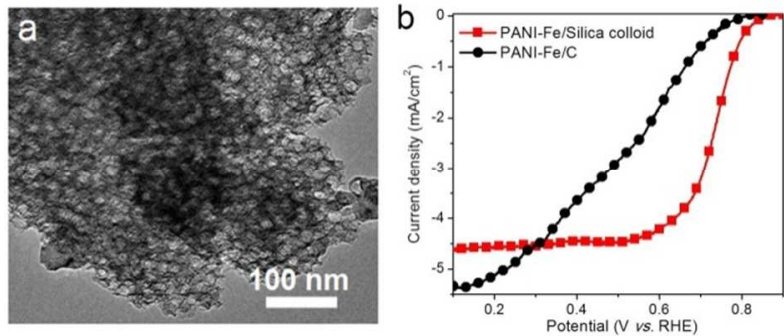

Figure 3. (a) TEM image of the mesoporous PANI-Fe/Silica colloid catalysts. (b) ORR polarization plots measured with different C-N-Fe catalysts.

In summary, we developed a family of mesoporous C-NCo and C-N-Fe catalysts by employing silica colloid, ordered mesoporous silica SBA-15, and montmorillonite as templates for realizing the mesoporous structures. The most active mesoporous catalyst (VB12/Silica colloid) exhibited high ORR activity (half-wave potential $0.79 \mathrm{~V}$ ), high selectivity (electron transfer number $>3.95$ ), and excellent electrochemical stability in acidic medium. The outstanding ORR performance of the prepared NPM catalysts is strongly associated with their well-defined mesoporous structures, high BET surface area, and homogenous distribution of numerous metal/nitrogen active sites. The concept of the mesoporous structure control demonstrated here is attractive for broad applications requiring both a high surface area and easy mass transport, such as supercapacitors, batteries, and heterogeneous catalysis.

\section{ASSOCIATED CONTENT}

\section{Supporting Information}

Experimental section and additional data. This material is available free of charge via the Internet at http:// pubs.acs.org.

\section{AUTHOR INFORMATION}

\section{Corresponding Author}

feng@mpip-mainz.mpg.de; muellen@mpip-mainz.mpg.de Notes

The authors declare no competing financial interests.

\section{ACKNOWLEDGMENT}

Financial support by ERC Grants on NANOGRAPH and 2DMATER, the Max Planck Society through the ENERCHEM Program, DFG MU 334/32-1, DFG Priority Program SPP 1459, ESF Project GOSPEL (9EuroGRAPHENE-FP-001), EU Project GENIUS, and EC Graphene Flagship (CNECT-ICT-604391) are acknowledged.

\section{REFERENCES}

(1) (a) Gasteiger, H. A.;Panels, J. E.;Yan, S. G., J. Power Sources 2004, 127, 162-171; (b) Sealy, C., Mater. Today 2oo8, 11, 65-68.

(2) (a) Gong, K. P.;Du, F.;Xia, Z. H.;Durstock, M.;Dai, L. M., Science 2009, 323, 760-764; (b) Liu, R. L.;Wu, D. Q.;Feng, X. L.;Müllen, K., Angew. Chem. Int. Ed. 2010, 49, 2565-2569; (c) Yang, W.;Fellinger, T.-P.;Antonietti, M., J. Am. Chem. Soc. 2010, 133, 206-209; (d) Yang, S.;Feng, X.;Wang, X.;Müllen, K., Angew. Chem. Int. Ed. 2011, 123, 5451-5455; (e) Liang, J.;Jiao, Y.;Jaroniec, M.;Qiao, S. Z., Angew. Chem. Int. Ed. 2012, 51, 11496-1150o; (f) Liang, J.; Zheng, Y.; Chen, J.; Liu, J.; Hulicova-Jurcakova, D.; Jaroniec, M.; Qiao, S. Z., Angew. Chem. Int. Ed. 2o12, 51: 38923896.

(3) Tewari, A.;Sambhy, V.;Urquidi Macdonald, M.;Sen, A., J. Power Sources 2oo6, 153, 1-10.

(4) Jaouen, F.;Proietti, E.;Lefevre, M.;Chenitz, R.;Dodelet, J. P.;Wu, G.;Chung, H. T.;Johnston, C. M.;Zelenay, P., Energy Environ. Sci. 2011, 4, 114-130.

(5) (a) Lefevre, M.;Proietti, E.;Jaouen, F.;Dodelet, J. P., Science 2009, 324, 71-74; (b) Proietti, E.;Jaouen, F.;Lefèvre, M.;Larouche, N.;Tian, J.;Herranz, J.;Dodelet, J.-P., Nat. Commun. 2011, 2, 416; (c) Wu, G.;More, K. L.;Johnston, C. M.;Zelenay, P., Science 2011, 332, 443-447; (d) Chang, S.-T.;Wang, C.-H.;Du, H.-Y.;Hsu, H.C.;Kang, C.-M.;Chen, C.-C.;Wu, J. C. S.;Yen, S.-C.;Huang, W.F.;Chen, L.-C. et al., Energy Environ. Sci. 2012, 5, 5305-5314; (e) Kramm, U. I.;Herrmann-Geppert, I.;Bogdanoff, P.;Fiechter, S., J. Phys. Chem. C 2011, 115, 23417-23427; (f) Pylypenko, S.;Mukherjee, S.;Olson, T. S.;Atanassov, P., Electrochim. Acta 2008, 53, 7875-7883. (g) Jaouen, F.; Herranz, J.; Lefevre, M.; Dodelet, J. P.; Kramm, U. I.; Herrmann, I.; Bogdanoff, P.; Maruyama, J.; Nagaoka, T.; Garsuch, A.; Dahn, J. R.; Olson, T.; Pylypenko, S.; Atanassov, P.; Ustinov, E. A., ACS Appl. Mater. Interfaces 2009, 1 (8), 1623-1639. (h) Herrmann, I.; Kramm, U. I.; Radnik, J.; Fiechter, S.; Bogdanoff, P., J. Electrochem. Soc. 2009, 156 (10), B1283-B1292.

(6) Lefèvre, M.;Dodelet, J.-P., Ecs Transactions 2012, 45, 35-44.

(7) Bakandritsos, A.;Steriotis, T.;Petridis, D., Chem. Mater. 2004, 16, 1551-1559.

(8) (a) Nabae, Y.;Moriya, S.;Matsubayashi, K.;Lyth, S. M.;Malon, M.;Wu, L. B.;Islam, N. M.;Koshigoe, Y.;Kuroki, S.;Kakimoto, M. A. et al., Carbon 2010, 48, 2613-2624; (b) Koslowski, U.;Herrmann, I.;Bogdanoff, P.;Barkschat, C.;Fiechter, S.;Iwata, N.;Takahashi, H.;Nishikori, H., Ecs Transactions 2oo8, 13, 125-141.

(9) Wu, G.;Johnston, C. M.;Mack, N. H.;Artyushkova, K.;Ferrandon, M.;Nelson, M.;Lezama-Pacheco, J. S.;Conradson, S. D.;More, K. L.;Myers, D. J. et al., J. Mater. Chem. 2011, 21, 1139211405 .

(10) Zhao, Y.;Watanabe, K.;Hashimoto, K., J. Am. Chem. Soc. 2012, 134, 19528-19531.

(11) Lee, K. T.;Ji, X. L.;Rault, M.;Nazar, L. F., Angew. Chem. Int. Ed. 2009, 48, 5661-5665.

(12) Wu, G.; Chen, Z. W.; Artyushkova, K.; Garzon, F. H.; Zelenay, P., Ecs Transactions 2oo8, 16, 159-170.

(13) Silva, R.; Voiry, D.; Chhowalla, M.; Asefa, T., J. Am. Chem. Soc. 2013, 135, 7823-7826.

(14) (a) Liang, Y. Y.; Li, Y. G.; Wang, H. L.; Zhou, J. G.; Wang, J.; Regier, T.; Dai, H. J., Nat. Mater. 2o11, 10, 780-786; (b) Jahnke, H.; Schönborn, M.; Zimmermann, M., Top. Curr. Chem., 1976, 61, 133-182.

(15) Ferrandon, M.;Kropf, A. J.;Myers, D. J.;Artyushkova, K.;Kramm, U.;Bogdanoff, P.;Wu, G.;Johnston, C. M.;Zelenay, P., J. Phys. Chem. C 2012, 116, 16001-16013;

(16) Ziegelbauer, J. M.;Olson, T. S.;Pylypenko, S.;Alamgir, F.;Jaye, C.;Atanassov, P.;Mukerjee, S., J. Phys. Chem. C 20o8, 112, 88398849 .

(17) Garsany, Y.;Baturina, O. A.;Swider-Lyons, K. E.;Kocha, S. S., Anal. Chem. 2010, 82, 6321-6328.

(18) Bonakdarpour, A.; Lefevre, M.; Yang, R.; Jaouen, F.; Dahn, T.; Dodelet, J.-P.; Dahn, J. R., Electrochem. Solid-State Lett. 2008, 11, B105-B108.

(19) Li, Y.;Zhou, W.;Wang, H.;Xie, L.;Liang, Y.;Wei, F.;Idrobo, J.C.;Pennycook, S. J.;Dai, H., Nat. Nano. 2012, 7, 394-400. 
$\overline{\text { Mesoporous Metal-Nitrogen-Doped Carbon Electrocatalysts for Highly Efficient Oxygen Reduc- }}$ tion Reaction

Hai-Wei Liang, Wei Wei, Zhong-Shuai Wu, Xinliang Feng, and Klaus Müllen

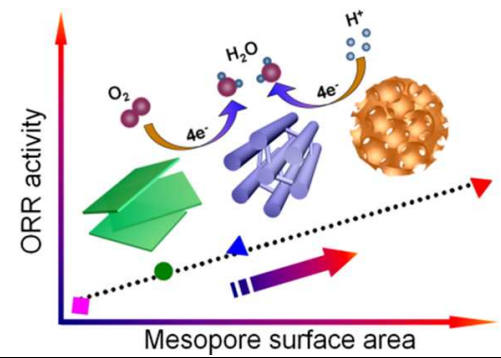

2

3

4

5

6

7

8

9

10

11

12

13

14

15

16

17

18

19

20

21

22

23

24

25

26

27

28

29

30

31

32

33

34

35

36

37

38

39

40

41

42

43

44

45

46

47

48

49

50

51

52

53

54

55

56

57

58

59

60 